2. По мере движения ТО по ТРР под действием износа его исходная ЭлЭ непрерывно снижается и представляет в каждый момент времени переменную - потенциальную - ЭлЭ.

3. То, какую часть реализуемая фактическая ЭлЭ ТО составляет от потенциалььнй, зависит от способа управления этим объектом. Особенности способа ущравления ТО сущесгвенно влияют на их фактическую ЭлЭ.

4. Наяболее высокой эффективностью обладает гибкий способ управления. Однако ему свойственна некоторая сложность. Он перспективен особенно для производства, нуждаюпегося в особо высоком качестве управления.

5. Относительно невысокой эффективностью характеризуется наиболее простой в реализации традиционный способ.

6. Эффективность способа полугибкого управления с помощью периодического корректирования алгоритма регулятора может быть сделана близкой эффективности способа гибкого. Этот способ характеризуется повышенной перспективностью в сфере производства с высокими требованиями к качеству управления.

7. Применение полугибкого и, особенно, гибкого управления, ло сравнению о традиционным, требуют увеличенного вложения ресуров. Однако, их превосходит положительный эффект, обусловленный значительным повышением качества управления и увеличением ресурса ТO.

\title{
Литература
}

1. Воінова С.О. Можливості управління екологічнољо характеристикою технічних об'єктів. // Тр. 11-ой Междунар. н.-т. конф. «Физич. и компьютерн. технологии» (02-03 июня 2005 г., Харьков). - Харьков: ХНПК «ФЭД》. $-2005 .-$ С. 221-223.

2. Воннова С.А. Актуальные задачи управления экологической эффективностью технических объектов. // Матер. Междунар. конф. «Стратегия качества в промышленности и образовании». (1-8 июня 2007 г., г. Варна, Болгария). - Днепропетровск - Варна: «Фортуна». - ТУ Варна. - 2007. - Т. 1. - С.102-104.

3. Воннова С.А., Сычук Л.М. Пути непосредственного управления экологической эффективностыю котельнотопочных систем. // Наукові праці ОНАХТ. - Мін. освіти і науки Украйни. - Одеса, 2007. - Вип.. 31. - Т.1. C. 159-161.

УДК: $621.57-53$

\section{АНАЛИЗ ВЛИЯНИЯ ПРОБНЫХ ДВИЖЕНИЙ ВБЛИЗИ ТОЧКИ ЭКСТРЕМУМА НА ПЕРЕХОДНЫЕ ПРОЦЕССЫ В ХОЛОДИЛЬНОЙ УСТАНОВКЕ}

\author{
Гурский А.А., аспирант \\ Одесская государственная академия холода, г. Одесса
}

B статье отражены идеи реапизаиии системы поиска экстремуяа при многоуровневой координиружией системе управления. Предспавлены результапы математических эксперинентов, направленных установить влияния пробных движений вбпзи точки экстремума на переходные процессы в холодильной установке.

It is considered realizations of search of an extremum at a coordinating control system. Results of mathematical experiments of the trial movements connected with influence near to a point of an extremum are presented.

Ключевые слова: координирующая система управления, компрессор, экстремум, расчетный блок.

\section{Введение}

Применение комбинированного регулирования производительности центробежного турбокомпрессора (ЦБК) холодильной установки по двум управляющим воздействиям, по углу установки лопаток диффузора $\alpha_{д}$ и по скорости вращения вала $n_{v}$, позволяет получить нанбольшее значение $\eta$ КПД турбокомпрессора и наименьшую потребляемую мощность $N_{L L K}$ [1]. Беспонсковая система, реализующая комбинированное регулированис производительности ЦБК с целью получения наибольшего значение $\eta$ КПД, имеет преимущество по сравнению с поисковой системой, связанное с отсутствие поиска и недостаток - возможность выхода в точку недостоверного экстремума КПД ЦБК.

В настоящей работе отражается идея реализацин поисковой системы ири многоуровневых (координирующих) систем управления холодильной турбокомпрессорной установкой (ХТУ) [2,3]. Проводиться ряд математических экспериментов для определения влияния пробных движений вблизи точки экстремума на переходные процессын.

Основная часть

Разработанные разлючные модели многоуровневых систем уиравления, а именно координирующая система $(\mathrm{KCУ})$ и система управления с расчетным блоком (РБ), реализуют комбинированное регулирование 
производительности холодильной турбокомпрессорной установки. Общая особенность этих систем заключается в том, что они выдерживают заданное функшиональное соотношение между углом установки лопаток диффузора $\alpha_{\not}$ и скоростью вращения вала $n_{v}$ при необхоцимой производительности компрессора. Функциональное соотношение представим в виде [2]:

$$
\varphi=A^{O} \cdot\left[\begin{array}{ll}
\alpha_{A} & n_{v}
\end{array}\right]^{T}+b
$$

где: $\varphi$ - невязка функционального соотношения;

$\dot{A}^{\dot{O}}=\left[\begin{array}{ll}\dot{a}_{1} & \dot{a}_{2}\end{array}\right]$-матрицы коэффициентов функционального соотношения;

$b$ - свободный член являюцийся функцией от степени сжатия $\pi_{k}$ ЦБК.

Данное заданное функциональное соотношение, которое устанавливает наибольшее значение КПД и наименьшую потребляемую мощность, определяется по газодинамическим характеристикам центробежного компрессора.

На рис. 1 представлена упрощенная структурная схема многоуровневой системы управлсния ХТУ. На верхнем уровне контуры регулирования с регуляторами 1.2 обеспечивают стабилизацию давлений кипения $P_{\text {киn }}$ и конденсации $P_{\kappa}$, а на нижнем уровне реализуется комбинированное регулирование производительности ХTУ. Структура нижнего уровня непосредственно определяет снстему, а именно координирующую или САУ с расчетным блоком.

Как было уже установлено функциональнос соотношсние между $\alpha_{д}$ и $n_{v}$, КСУ выдерживает [3], но при этом могут сушествовать некоторые сомнения в том, что именно данное функцнональное соотношение способно определить режим работы, который характеризуется минимальным (максимальным) значением показателя качества. Таким образом функциональное соотношение между углом установки лопаток диффузора $\alpha_{д}$ и скоростью вращения вала $n_{v}$ целесообразно корректировать в процессе работы системы с целью поиска достоверного экстремума показателя эффективности функционирования $\left(N_{L \text { цбK }} \rightarrow\right.$ mi1 $)$.

Реализация понсковой системы в рамках дополнения координирующей системы или системы с расчетным блоком возможна, но при этом следует учесть, что данная система имест отличие от традиционных экстремальных скстем. Системы экстремального управления и методы поиска экстремума как дегерминированные, так н случайные имеют особенность изменять управляюшие параметры с целью поиска минимальното (максимального) показателя качества. В настояшем случае поисковая система будет изменять функциональное соотношение, а именно корректировать коэффициенты, определяющие соотношенне мсжду параметрами. А корректнровка коэффициентов функционального соотношения будет в свою очередь влиять на нзменение величин управлятоцих воздействий $u_{2 \alpha_{\text {. }}}$ и $u_{3 n_{v}}$.

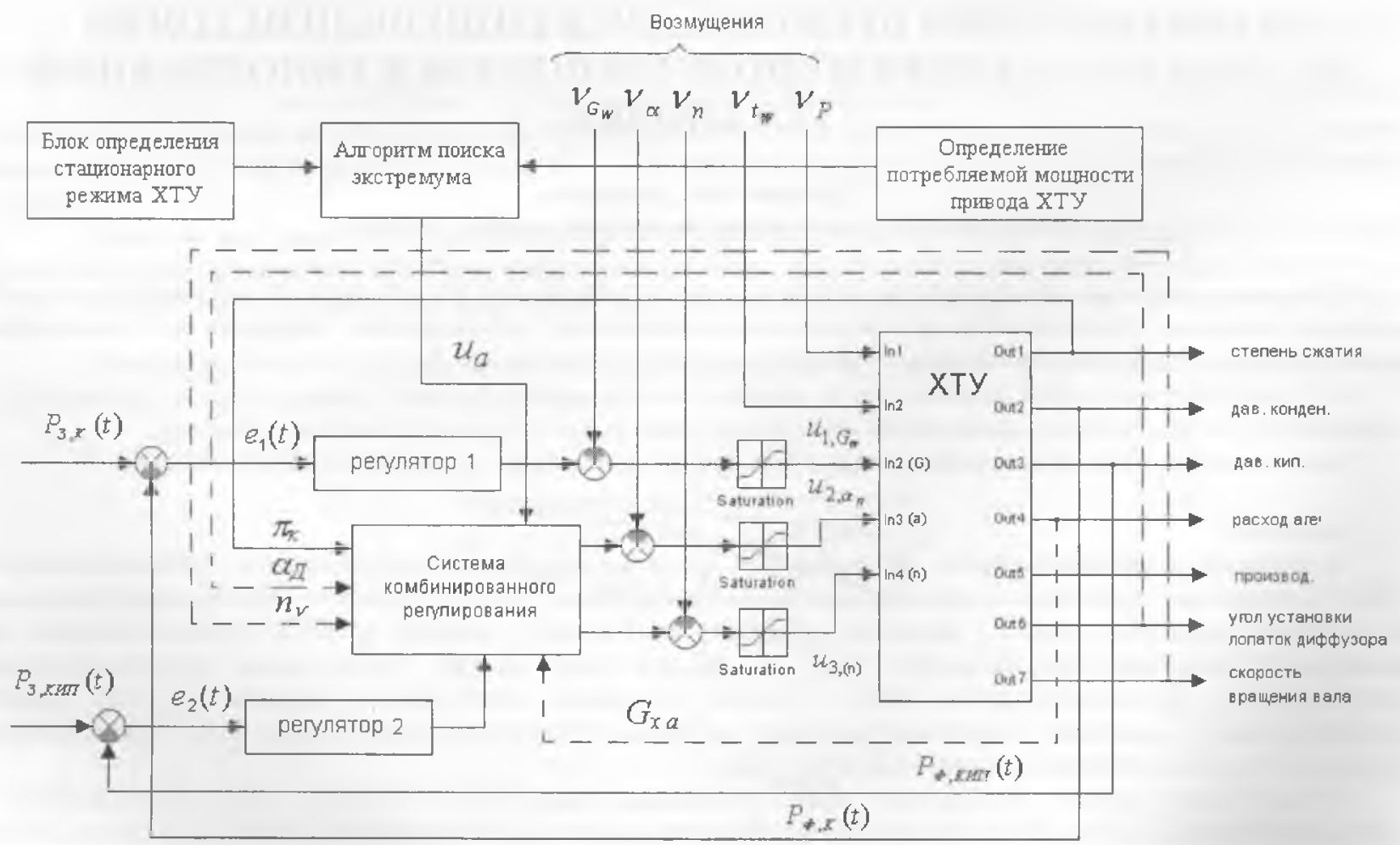

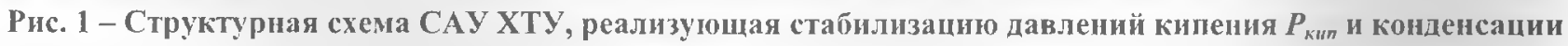
$\boldsymbol{P}_{k}$ и комб́инированное регулирование произодительности ЩБК; $\boldsymbol{u}_{a}$-воздействие для корректировки парамстра а регулируемого соотношения; пунтирной линией - обратиые связи при КСУ ХГУ 
Построение экстрсмальной системы и определение зоны понска и времени выхода в точку экстремума будет уместно после проведенця определеншых математических экспериментов. Данные математические эксперименты направлены на то. чтоб установить влияния пробных движеннй вблизи точки экстремума на переходные процессы в координируюцей системе. Параметрами регулируемого функционального соотношения в координирующей системе являются элементы матрицы $A^{0}$ и свободный член $b=f\left(\pi_{\kappa}\right)$.

Эксперименты проведены следующим образом: При ненулевых начальных условиях посредством КСУ

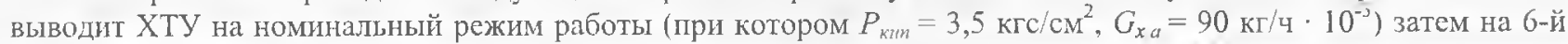
мин. изменяем параметры (رункционального соотношения (элементы матрицы $A^{O}$ и $b$ ). По полученным графнкам переходных процессов представленных на рис. 2 - 4 видно, что существенная корректировка элементов матрицы $\dot{A}^{O}$ практически не приводит к переходному процессу по массовому расходу холодильного агента при КСУ ХТУ. Следовательно, пробные движения вблизи точки экстремума не будут вльять на изменение давления кипения $P_{\text {кил. }}$. Но при САУ ХТУ с РБ будет малозаметный переходной процесс по давлению кипения $P_{\text {ки }}$ (отклонение давления не б́лее $1 \%$ от заданного знахения). Несущественное различие в влиянии пробных движений на переходной процесс по давлению кипения $P_{\text {ки }}$ связано с тем, что в КСУ ХТУ, в отличии от САУ ХТУ с РБ, присутствует отрицательная обратная связь по массовому расходу холодильного агента $G_{x \rightarrow r}$ (на рис. 1 представлена пунктирной линией) и внутренний подчиненньгй контур регулирования пронзводительности ЏБК.

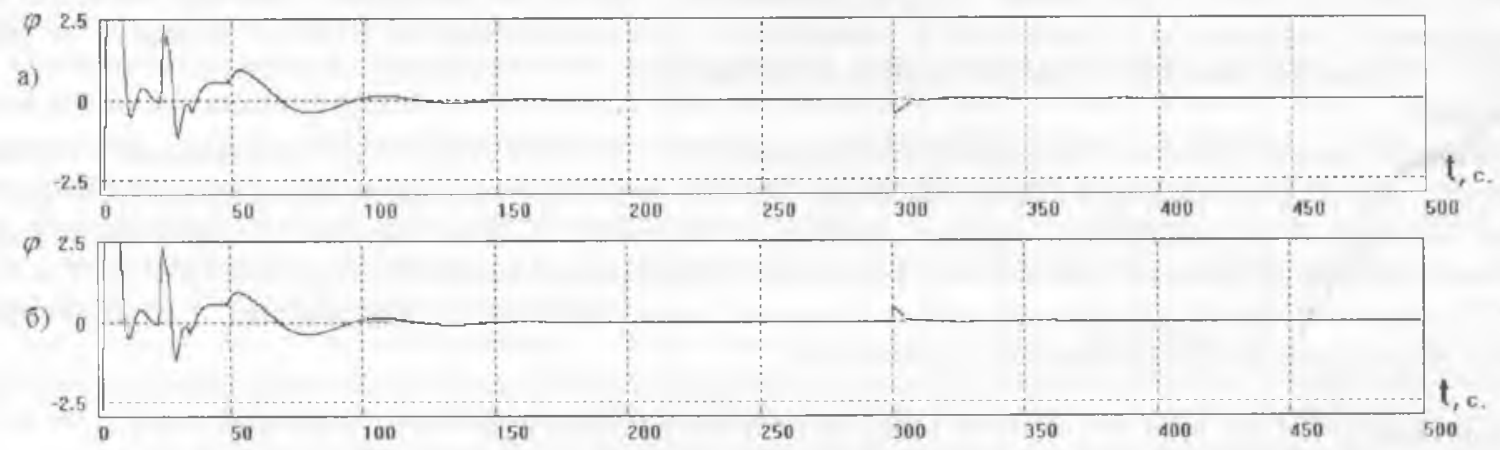

Рис. 2 - Графики изменеии невлзки ф во времени при корректировке на 300 сек. коэффициентов регулируемого соотношения в КСУ ХТУ; а) параметр а, уменьшен на 5\%; б) а увеличен на $5 \%$

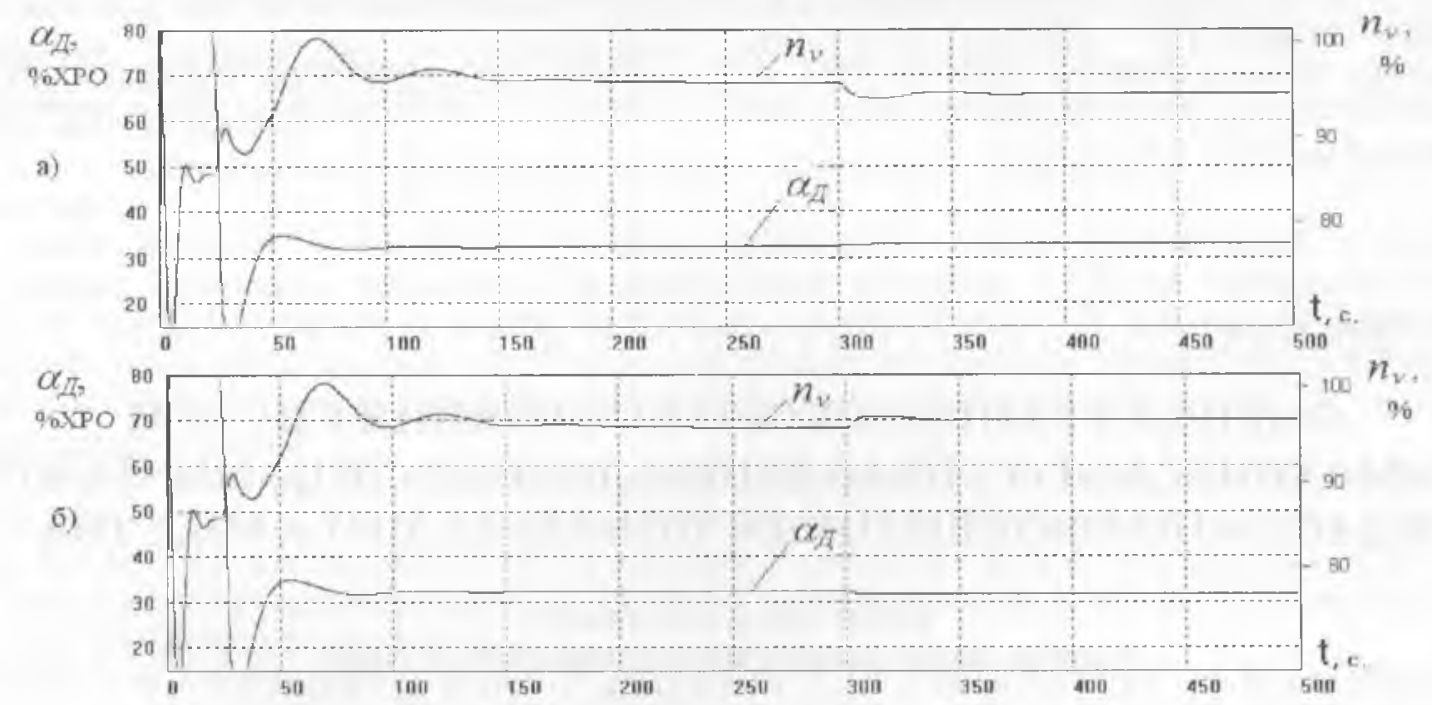

Рис. 3 - Графики изменения угла установки лопаток диффузора $\alpha_{d}$ и скорости врашения вала $n_{v}$ во времени при корректировке на 300 сек. коэффициентов регулируемого соотношения в КСУ ХТУ. а) параметр а уменишен на $5 \%$; б) а у увеличен на $5 \%$ 


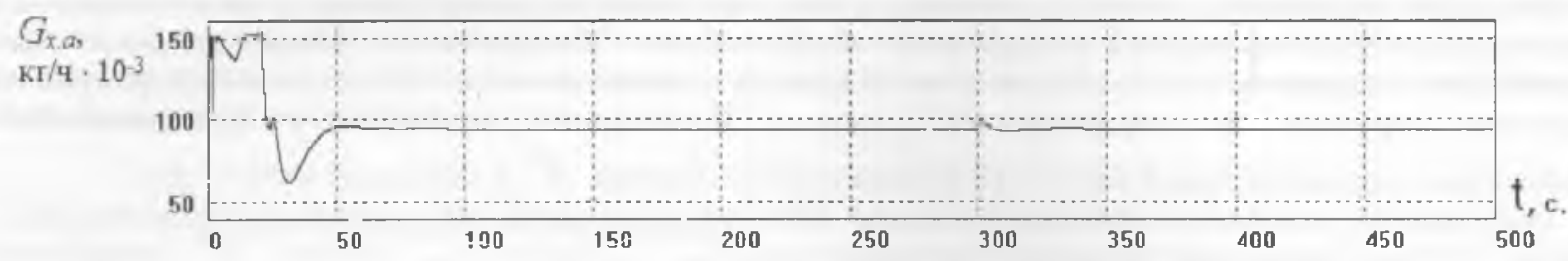

Рис. 4 - Переходной процесс по расходу холодильного агента $G_{x, a}$ ири корректировке на 300 сек. коэффиниентов регулируемого соотношения в КСУ ХТУ

Таким образом, возможна реализация поиска экстрсмума при КСУ ХТУ и САУ ХТУ с РБ в частности способом случайного понска который целесообразен при небольшом числе изменяемых параметров. Суть данного способа при КСУ ХТУ и САУ ХТУ с РБ заключается в поиске экстремума за счет случайного изменения параметра $\mathrm{a}_{1}$. В начальном состоянии системы при стационарном режиме вынолняется прирост

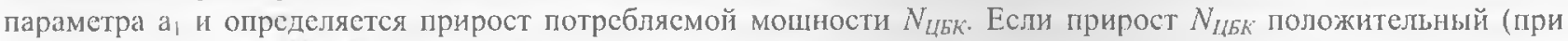
поиски минимума $N_{l b 6}$ ) то система поиска возвращает парамстр а на начальное заданнос значение и

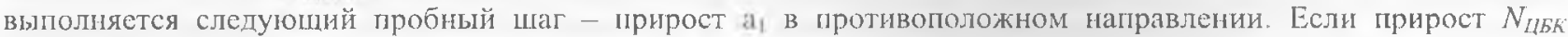
обратно положительный, то считаем что $N_{L L B K}=\min$ и ноиск экстремума прекрашается. Если прирост $N_{L ь 5 K}$ получился отрицательным то при новом скорректированном $a_{1}$ делаются пов горные пробные шаги. Но ири этом если режим динамический связанный с изменением производительности ЦБК то параметр а исходному - заданному значению и система поиска отключается.

\title{
Выводы
}

Проведенные математические эксперименты на моделях КСУ ХТУ и САУ ХТУ с РБ позволили установить црактическое огсутствие влияния пробных движений вблизи точки экстремума на пгереходные процессы по давлению кипения и по массовому расходу холодильного агента. Таким образом, в настояшей работе отраженная идея и подход реализации поиска экстремума потребляемой мошиости $N_{Ц б к}$ при КСУ ХТУ и САУ ХТУ с РБ дает возможность установить ряд актуальных задач связанных с реализацией и исследованием различных моделей систсм экстремального управления.

\section{Литература}

1. Сухомлинов И.Я., Савельева И.Ю., Головин М.В. Исследование методов регулирования параметров холодильных машин с центробежными компрессорами. // Химическое и нефтяное машиностроение. - 1995. - №11 - C. 29-36.

2. Бойчук Л.М. Синтез координирующих систем автоматического управления. - М.: Изд-во «Энсргоатомиздат», 1991. - $160 \mathrm{c}$.

3. Денисенко В.А., Гончаренко А.Е., Козорез А.Н., Гурский А.А. Комбинированное регулирование производительности турбокомпрессора холодильной установки. // Холодилыная техника и технология, № 6, 2007 г. - с. 93-96.

\section{ОЦЕНКА ТЕХНИЧЕСКОГО СОСТОЯНИЯ СИСТЕМ АВТОМАТИЧЕСКОГО УПРАВЛЕНИЯ ЛОГИКО-ДИНАМИЧЕСКОГО КЛАССА ПО ОБОБЩЕННЫМ ПОКАЗАТЕЛЯМ КАЧЕСТВА}

\author{
Енчев C.В., к.т.н., доцент \\ Наџнональный авиационный университет, г. Киев
}

На основе прямого метода оценки качества функинонирования систем сформирован обобијенный показатель качсства фуикиионирования систел автолатического управления логико-диналического класса. $C$ его помоцью сфориирована область безотказной работы с подоблистью настройки системы автоматического управления.

On the basis of direct method of estimation quality functioning of the systems the generalized index of quality of functioning of the automatic control systems of logical-dynamic class is formed. With his help the region of faultless work is formed with area of uning of the automatic control system.

Ключевые слова: техническое состояние, система автоматического управлсния, обобщенный показатель качсства. 